ments in small animals. J Appl Physiol 40:275-277

12. Wagner PD, Nauman PF. Lareruso RB 1974 Simultaneous measurement of eight foreign gases in blood by gas chromatography. J Appl Physiol 36:600605

13. Hlastala MP, Robertson HT 1978 Inert gas elimination characteristics of the normal and abnormal lung. J Appl Physiol 44:258-266

14. Copley DP, Klocke RA, Klocke FJ 1976 Quantitation of right to left shunt by double indication and oxygen techniques. J Appl Physiol 44:409-415

15. Hoffman JIE, Heymann MA, Rudolph AM, Payne BD 1977 Uses and abuses of the radioactive microsphere method of measuring regional blood flow. Bibl Anat 14:20-23

16. Zar JA 1974 Multiple comparisons. In: Biostatistical Analysis. Prentice-Hall Inc., Englewood Cliffs, NJ, pp 151-155
17. Haworth SG, Hislop AA 1981 Adaptation of the pulmonary circulation to extra uterine life in the pig and its relevance to the human infant. Cardiovasc Rev 15:108-119

18. Peake MD, Harabin AL, Brennan NJ, Sylvester JT 1981 Steady-state vascular responses to graded hypoxia in isolated lungs of five species. J Appl Physiol $51: 1214-1215$

19. Marshall BE, Marshall C 1980 Continuity of response to hypoxic pulmonary vasoconstriction. J Appl Phys 49:185-196

20. Tucker A, Reeves JT, Jackson DL, Grover RF 1978 Decreased pulmonary vascular responses in dogs with increased pulmonary blood flow. Can J Physiol Pharmacol 56:1011-1016

21. Sylvster JT, Harabin AL, Peake MD, Frank RS 1980 Vasodilator and constrictor responses to hypoxia in isolated pig lungs. J Appl Physiol 49:820-825

\title{
Effect of Bilirubin on Brainstem Auditory Evoked Potentials in the Asphyxiated Rat
}

\author{
JOHN H. JIRKA, R. BRADFORD DUCKROW, JAMES W. KENDIG, AND M. JEFFREY MAISELS \\ Division of Newborn Medicine, Department of Pediatrics, and the Division of Neurology, Department of Internal \\ Medicine, The Milton S. Hershey Medical Center, The Pennsylvania State University, College of Medicine, \\ Hershey, Pennsylvania 17033
}

\begin{abstract}
We measured brainstem auditory evoked responses (BAER) in four groups of paralyzed, ventilated, adult rats. Group $A(n=2)$ received intravenous albumin; group $B(n=5)$ received bilirubin in albumin; group $C(n$ $=7$ ) was asphyxiated and then received albumin; and group $\mathrm{D}(n=19)$ was asphyxiated and received bilirubin in albumin. When compared with control values, no changes in BAER occurred in groups A or B and only slight changes were found in group $C$. In group D, seven rats died and seven suffered a marked secondary deterioration of the BAER following recovery, a phenomenon that did not occur in group $C(p=0.02)$. Bilirubin toxicity appears to be responsible for the changes in BAER but prior asphyxia was necessary for this effect to occur. Because the changes that occurred in group D involved all four major waves, it is not possible to separate out a toxic effect of bilirubin, localized to the auditory nerve and the auditory pathway, from a generalized systemic effect which could cause attenuation of the entire response. The BAER may be useful, however, as a noninvasive means of identifying bilirubin toxicity in the newborn. (Pediatr Res 19: 556-560, 1985)
\end{abstract}

\section{Abbreviation}

BAER, brainstem auditory evoked response

BAER is the sound induced farfield reflection of electrical events generated within the auditory pathway in its progressive path through the brainstem (1-3). Because neurons of the cochlear nuclei and inferior collicular nuclei are sensitive to bilirubin

Received June 25, 1984; accepted February 6, 1985

Requests for reprints may be addressed to M. Jeffrey Maisels, M.D., Department of Pediatrics, The Milton S. Hershey Medical Center, Box 850, Hershey, PA 17033. injury $(4,5)$ and contribute to waveforms in the BAER, auditory evoked potentials might be useful in the detection of early bilirubin toxicity $(6-8)$

In most animal species, hyperbilirubinemia alone fails to produce kernicterus. However, when hyperbilirubinemia is accompanied by an additional insult to the central nervous system (such as asphyxia), kernicterus may occur (9-11). We examined the effect of hyperbilirubinemia on the BAER in the adult rat, in the presence and absence of asphyxia.

\section{SUBJECTS AND METHODS}

Adult male Hooded Long-Evans rats, weighing 252 to $429 \mathrm{~g}$, were studied. Pentobarbital, $65 \mathrm{mg} / \mathrm{kg}$ body weight, was injected intraperitoneally for anesthesia. Blood gases and arterial blood pressure were measured via a femoral artery catheter. Intravenous injections of albumin or bilirubin in albumin were given via a catheter in the femoral vein. Temperatures were servocontrolled by means of a rectal probe and warming lamp. Tracheostomies were performed on all animals prior to mechanical ventilation with a Harvard Rodent Respirator no. 680. Tubocurarine, 2.5 to $3.0 \mathrm{mg} / \mathrm{kg}$ body weight, was injected intraperitoneally to minimize movement artifact on the evoked potential recording and arterial blood gases were maintained at established norms (12).

Far-field short-latency brainstem potentials were recorded from a vertex active needle electrode and a jaw needle electrode and amplified with a Grass P511J EEG amplifier bandpass filtered from 10 to $3000 \mathrm{~Hz}$. Click stimuli of $0.1 \mathrm{~ms}$ and $65.1 \mathrm{~dB}$ (SPL) were presented to the left ear at 10 clicks per second using a radio earphone (Radio Shack, no. 33-174) driven by $100 \mu \mathrm{S}$ square pulses of constant polarity. The radio earphone was calibrated with a Bruel and Kjaer (B \& K) type 2606 measuring amplifier coupled to a type 4152 artificial ear by means of a type 2627 preamplifier. AB \& K type 4144 pressure microphone was used in the artificial ear. Epochs of $10 \mathrm{~ms}$ were digitized at 10 
$\mathrm{KHz}$ and averaged using a TransEra analog to digital converter interfaced to a Tektronix 4052 desktop graphics computer system. Stimulus amplitude was below threshold for binaural interaction. The right ear canal remained patent. A stable brainstem auditory evoked potential with four major components was recorded similar to those reported by Jewett and Romano (2).

Absolute latencies are the intervals in msec from the onset of the auditory stimulus to each component peak. Amplitudes are the heights in microvolts measured from the baseline. Positivity of the vertex electrode relative to the jaw electrode was plotted upward (Figs. 1 to 3 ). The first two components of the BAER are positive waves with the second wave of greater amplitude. The third component is a biphasic wave with greater negative amplitude than positive amplitude. The fourth component is a positive wave with smaller amplitude than wave I or II. Frequently the fourth component was followed by one or two additional waves of low positive amplitude (Fig. 1). Three successive averages of responses to 200 click stimuli were superimposed for determination of amplitudes and latencies of the various component waves.

A control BAER was obtained on all rats after stabilization of

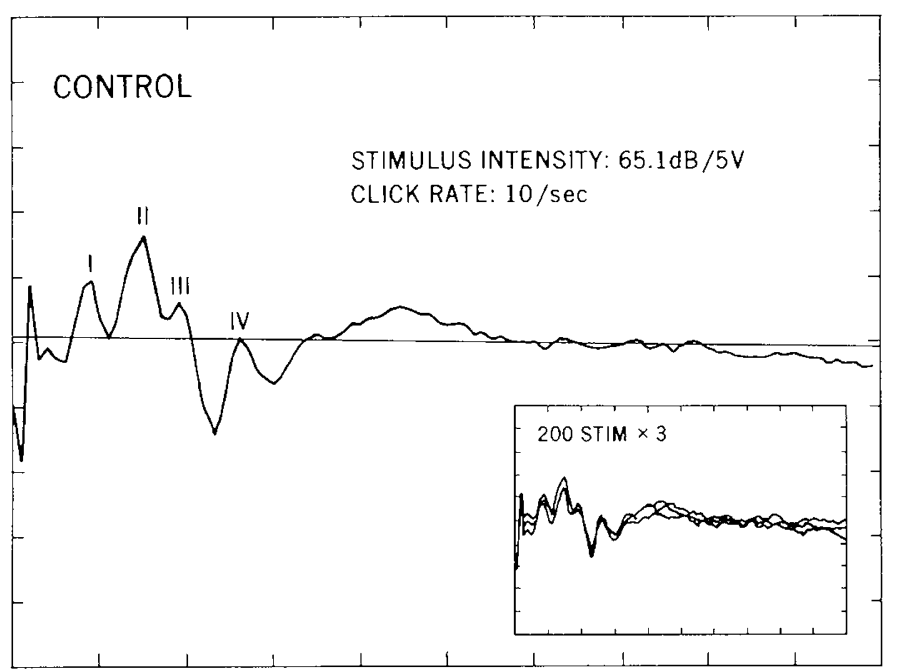

Fig. 1. Normal rat BAER with four major waves. The larger tracing represents the average of three successive responses (inset).

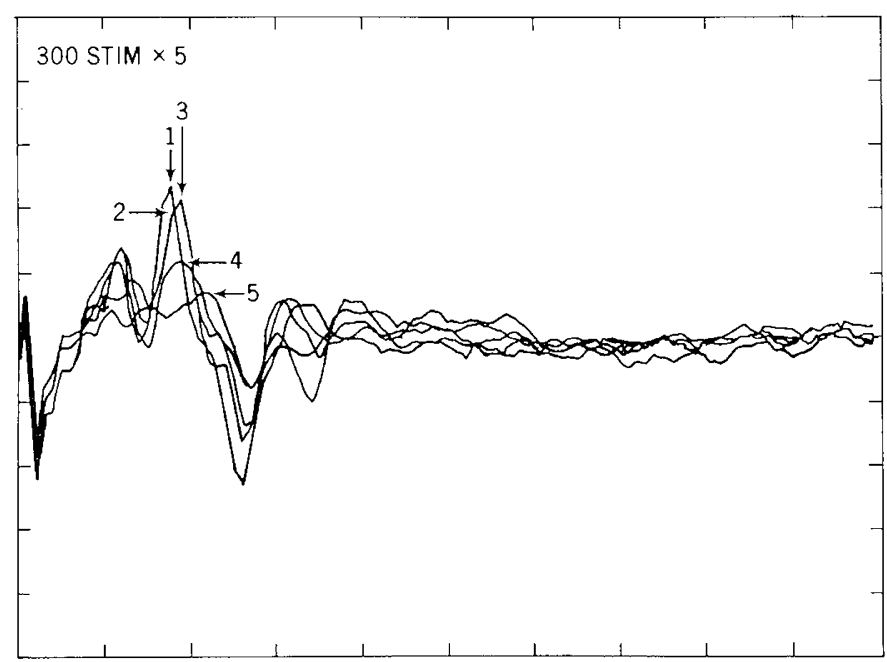

Fig. 2. BAER from a single rat representing five consecutive responses to 300 stimuli each during asphyxia showing increasing latencies and decreasing amplitudes. In the second and third responses there is superimposition of portions of wave II. the arterial blood gases. Following this, two rats received an intravenous infusion through the femoral vein of $25 \%$ bovine serum albumin, $10 \mathrm{ml} / \mathrm{kg}$ body weight (group A, Table 1). Five rats received the same volume of a solution of $7 \mathrm{mM}$ bilirubin in albumin prepared as described by Levine et al. (13) (group B, Fig. 4). Twenty-six rats (groups $C$ and D) were asphyxiated by turning off the respirator and clamping the inspiratory and expiratory tubing. From preliminary experiments, $4 \mathrm{~min}$ of asphyxia produced the maximum insult with the least mortality. Resuscitation by hyperventilation with $100 \%$ oxygen and external cardiac massage produced stable, normal blood gases within $15 \mathrm{~min}$ in surviving rats (Table 2). During the first $3 \mathrm{~min}$ of asphyxia, seven of these rats received an intravenous infusion of $1.5 \mathrm{mM}$ bovine serum albumin, $10 \mathrm{ml} / \mathrm{kg} /$ body weight (group C), while the other 19 received a similar volume of $7 \mathrm{mM}$ bilirubin in albumin (group D, Fig. 4). In groups A and B additional BAER recordings were obtained at 5, 15,30,45, and 60 min following the completion of the infusions. In groups $\mathrm{C}$ and $\mathrm{D}$ recordings were taken at similar intervals following the completion of the 4-min period of asphyxia.

Blood $(0.4$ to $0.5 \mathrm{ml})$ for determination of total plasma bilirubin levels was removed from the femoral artery catheter at 5 , 15,30 , and 60 min following the completion of the asphyxic period. Plasma bilirubin determinations were performed using the American Optical Bilirubinometer. Statistical analyses were performed using two sample or paired $t$ tests and Fisher's exact test.

\section{RESULTS}

In the 26 asphyxiated rats (groups $C$ and $D$, Tables 1 and 2) the BAER deteriorated during progressive asphyxia. Characteristically, there was a decrease in amplitudes and a prolongation of the absolute latencies of all wave components until by 4 min the BAER was abolished in all animals (Fig. 2). Abolition of the BAER always occurred when arterial blood pressure fell below 20 to $25 \mathrm{~mm} \mathrm{Hg}$ irrespective of the arterial blood gas status. With successful resuscitation and the restoration of blood pressure, the BAER returned to control values within $15 \mathrm{~min}$ of completion of the asphyxic period. Following asphyxia, increases in wave amplitude (particularly wave II) were noted occasionally. In group $C$ the absolute latency of wave I increased 60 min after asphyxia from a mean control value of 1.02 to $1.12 \mathrm{~ms}(p=$ 0.04 , one tailed $t$ test) but no other changes in latency were found in the other waves or at other times after recovery from asphyxia.

In the nonasphyxiated rats (groups $A$ and $B$, Table 1) there were no changes in the BAER following infusion of albumin or bilirubin in albumin. In group $C$ one rat could not be resuscitated, but in the other six rats the BAER returned to control values within $15 \mathrm{~min}$ of recovery from asphyxia.

Of the 19 rats who were asphyxiated and received bilirubin in albumin (group D, Table 1), seven (37\%) could not be resuscitated ( $p=0.27$ versus group C). In the remaining 12 rats, the BAER returned to control values within $15 \mathrm{~min}$. Seven of these 12 demonstrated a later, secondary deterioration, of the BAER with progressively decreasing amplitudes and prolonged absolıte latencies of all the component waves (group D2). None of the rats in group $C$ had a similar deterioration in BAER $(p=0.02$ versus group $\mathrm{D}$ ). The secondary deterioration was first detected on the 30-min tracing following resuscitation, and by $60 \mathrm{~min}$ the amplitudes of most waves were frequently less than $50 \%$ of control values (Fig. $3 A$ to $F$ ). Two rats had a flat BAER by 45 and $60 \mathrm{~min}$, respectively. The rats that demonstrated the secondary deterioration of the BAER (group D2) did not differ from those that had no such change (group D1) with respect to weight, temperature, blood pressure, serum bilirubin levels, or time of resuscitation. Blood gas values are shown in Table 2 . Following 3 min of asphyxia, rats in group D2 had a mean serum bicarbonate concentration of $18.1 \pm 1.0(\mathrm{SD})$ versus $22.4 \pm 1.7 \mathrm{mM} /$ liter in group D1 $(p<0.05)$. Bicarbonate concentrations in group $\mathrm{C}$ were virtually identical to group D2. Differences between 

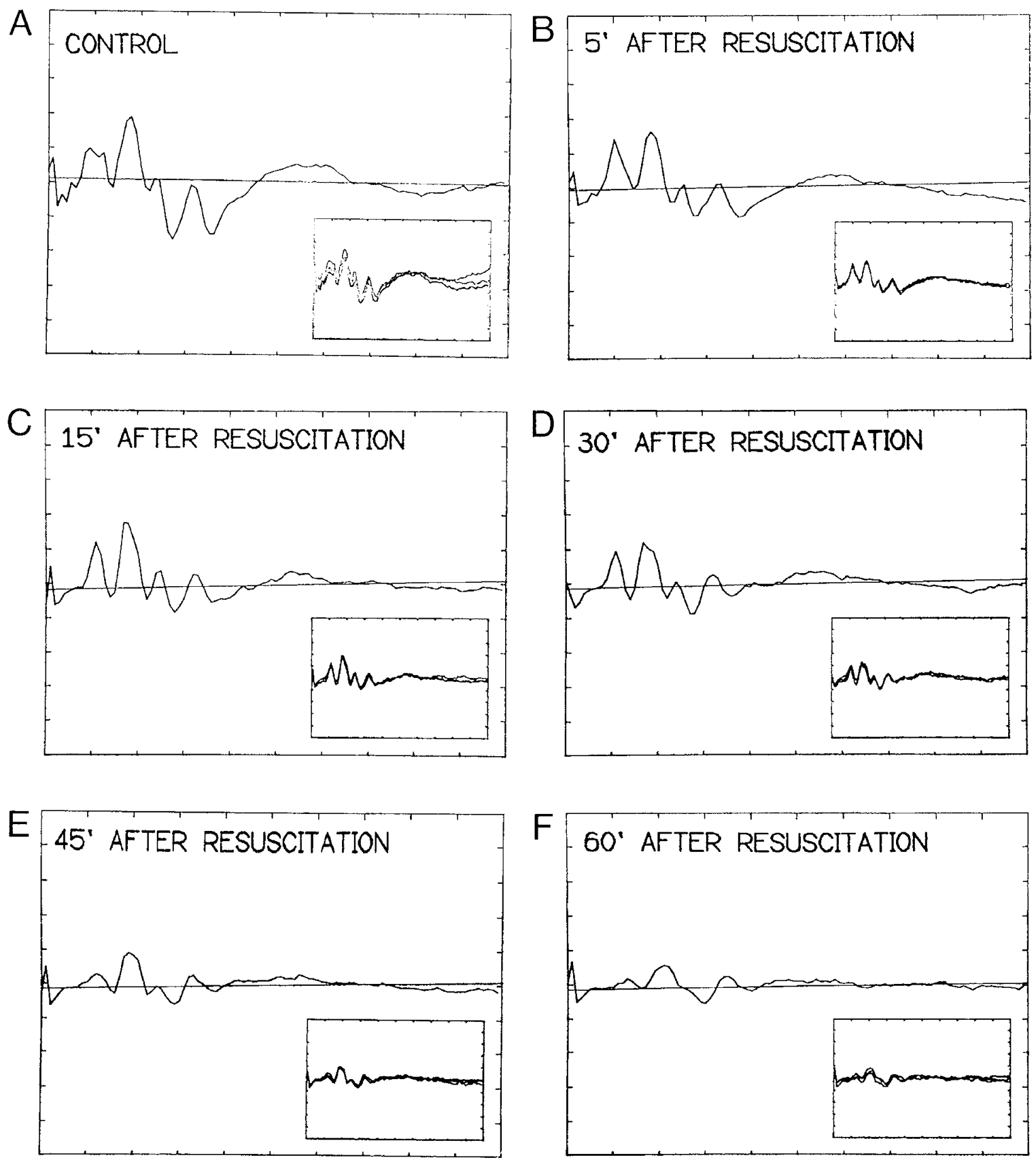

Fig. 3. $A-F$, the effect of asphyxia in the presence of hyperbilirubinemia. A rat from group $\mathrm{D}$ showing secondary deterioration of BAER following recovery from asphyxia. A, control BAER; B-F, BAER at different time intervals after resuscitation following 4 min of complete asphyxia. Note: recovery of previously abolished response (not shown) has commenced by $5 \mathrm{~min}$ and is complete by $15 \mathrm{~min}$. Progressive secondary deterioration of amplitude and latency occurs from $30-60 \mathrm{~min}(D-F)$.

groups D1 and D2 are probably a reflection of $\mathrm{PCO}_{2}$ differences, as would be expected in acute respiratory acidosis.

There were no significant differences in amplitudes or latencies between groups A, B, and C (after recovery from asphyxia). In group $\mathrm{D}$ the amplitude of wave 1 was significantly lower at 5 , 45 , and 60 min following asphyxia than in group $C(p<0.05)$ but no differences were found in wave II. In groups B and D bilirubin was cleared from the rats during the 1-h observation period, and there were no significant differences in serum bilirubin concentrations (Fig. 4).

During asphyxia, the EEG tracing flattened prior to the abolition of the BAER and reappeared only after the BAER was elicited again. However, the amplitude of the EEG tracing remained attenuated when compared with control amplitudes prior to asphyxia.
At autopsy, the asphyxiated animals who received bilirubin, demonstrated yellow serous or slightly hemorrhagic fluid accumulations of the pleural and abdominal cavities. Petechiae were frequently seen on the heart, lungs, and mucosa of the gastrointestinal tract. Yellow pulmonary edema was almost universally seen and frequently collected in the respiratory tubing during the $1-\mathrm{h}$ period. These systemic findings of bilirubin toxicity are similar to those reported by Rozdilsky and Olszewski (5). In contrast, the rats who received only bilirubin (without asphyxia) demonstrated yellow body fluids without evidence of hemorrhage, petechiae, exudations, or pulmonary edema. In rats who had received bilirubin infusions, there was no obvious yellow staining of brain parenchyma in those autopsied. Unfortunately, the brains were not perfused prior to examination so that yellow staining would likely be missed (5). 


\section{DISCUSSION}

We sought an objective, noninvasive means of detecting bilirubin neurotoxicity in adult rats. The infusion of bilirubin alone failed to produce changes from control values in the BAER over a period of 1-h. In most animal species studied, bilirubin infusions alone have failed to produce yellow staining of the brain or clinical evidence of neurotoxicity. Kernicterus may occur, however, if a central nervous system insult occurs in the presence of hyperbilirubinemia (9-11).

The progressive secondary deterioration in the BAER, first seen 30 min postresuscitation, was seen in $58 \%$ of the surviving asphyxiated animals who received bilirubin but in none of the other asphyxiated animals ( $p=0.02$, Fisher exact test) suggesting a role for bilirubin in the production of this effect. Although absolute latencies were prolonged in the group $\mathrm{D}$ rats, the rats that died, did so from circulatory collapse and pulmonary edema, possibly due to systemic bilirubin toxicity (5).

The exact mechanism for the bilirubin toxicity and subsequent secondary deterioration of the BAER is unknown. The secondary deterioration of the BAER involved all four major waves, suggesting that the toxicity affected either the cochlea/auditory nerve (represented by wave I) or the brainstem auditory pathway, reflected by subsequent waves. The primary changes were seen in wave amplitude, all amplitudes being decreased to a similar degree. This suggests that either the primary generator of the afferent volley (the cochlea) was suppressed, or that the individual

Table 1. Experimental design and results

\begin{tabular}{|c|c|c|}
\hline Experimental design & $n$ & Results \\
\hline Group $A$, no asphyxia + albumin & 2 & No change in BAER \\
\hline $\begin{array}{l}\text { Group B, no asphyxia + albumin/ } \\
\text { bilirubin }\end{array}$ & 5 & No change in BAER \\
\hline $\begin{array}{l}\text { Group C, asphyxia (4 min) } \\
\quad+\text { albumin }\end{array}$ & 7 & $\begin{array}{l}1 \text { died (unable to } \\
\text { resuscitate) } \\
6 \text { normal BAER } \\
\text { following resuscitation }\end{array}$ \\
\hline $\begin{array}{l}\text { Group D, asphyxia (4 min) } \\
+ \text { albumin/bilirubin }\end{array}$ & 19 & $\begin{array}{l}7 \text { died (unable to } \\
\text { resuscitate) } \\
5 \text { normal BAER } \\
\text { following resuscitation } \\
7 \text { secondary deterioration } \\
\text { of BAER following } \\
\text { resuscitation }\end{array}$ \\
\hline
\end{tabular}

wave generators (brainstem nuclei) were affected to a similar degree. Changes in waves III and IV were similar to those seen in waves I and II, but it was difficult to define their amplitudes because of their polyphasic nature relative to the electrical baseline used to define the amplitudes of waves I and II (see Fig. 1). Although absolute latencies increased, interwave latencies did not, suggesting that bilirubin did not affect central conduction velocities.

One possible mechanism for the production of bilirubin neurotoxicity is the disruption of the blood brain barrier, allowing temporary passage of albumin-bound bilirubin into the brain (14). Hyperosmolar solutions (5, 13-16), hypertension (7, 16), and hypercarbia (17-19) have been shown, experimentally, to alter the permeability of the blood brain barrier as have asphyxia (11) and hypoxic ischemic insults (9). Furthermore, studies in this laboratory have demonstrated that marked cerebral hyperemia occurs 30 min after recovery from (the ischemic changes of ) asphyxia in the newborn dog (20). If this occurred in these rats, large volumes of bilirubin-containing blood would impinge on a damaged blood brain barrier, allowing the bilirubin to enter the brain and produce the secondary deterioration seen in the BAER. Although bilirubin may have produced a direct toxic effect on

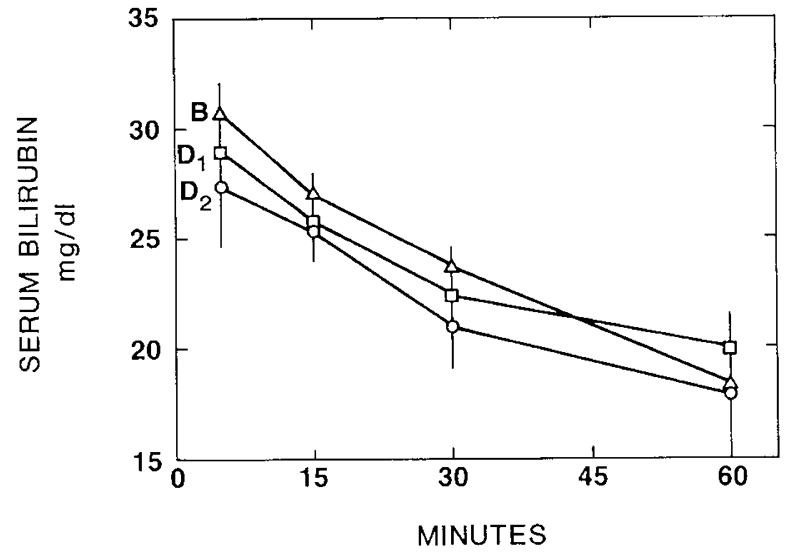

Fig. 4. Serum bilirubin concentrations (mean and $S D$ ) in groups $B$ and $D . D_{1}$ refers to five rats in group $D$ that had normal BAER following resuscitation. $\mathrm{D}_{2}$ refers to seven rats in group $\mathrm{D}$ that had secondary deterioration of BAER following resuscitation. None of the values at each time interval is significantly different from the others.

Table 2. Blood gas changes in surviving asphyxiated rats (groups $C$ and $D)^{*}$

\begin{tabular}{|c|c|c|c|c|c|c|}
\hline & \multirow[b]{2}{*}{ Preasphyxia } & \multirow{2}{*}{$\begin{array}{l}\text { Asphyxia } \\
\text { for } \\
3 \mathrm{~min}\end{array}$} & \multicolumn{4}{|c|}{ Postresuscitation (min) } \\
\hline & & & $10-15$ & $16-30$ & $31-45$ & $46-90$ \\
\hline \multicolumn{7}{|l|}{ Group C } \\
\hline $\mathrm{pH}$ & $7.41 \pm 0.039$ & $7.08 \pm 0.056$ & $7.39 \pm 0.069$ & $7.42 \pm 0.050$ & $7.42 \pm 0.048$ & $7.41 \pm 0.038$ \\
\hline $\mathrm{PCO}_{2}$ (torr) & $35.1 \pm 4.0$ & $66.3 \pm 20.0$ & $31.0 \pm 5.3 \dagger$ & $32.8 \pm 5.6$ & $35.8 \pm 7.6$ & $38.6 \pm 4.7$ \\
\hline $\mathrm{PO}_{2}$ (torr) & $116 \pm 18$ & $21 \pm 12$ & $111 \pm 24$ & $135 \pm 46$ & $127 \pm 43$ & $100 \pm 48$ \\
\hline $\mathrm{HCO}_{3}^{-}(\mathrm{mM} /$ liter $)$ & $21.3 \pm 3.0$ & $18.0 \pm 4.4$ & $17.8 \pm 2.4$ & $20.5 \pm 2.1$ & $21.8 \pm 3.2$ & $23.6 \pm 2.0$ \\
\hline \multicolumn{7}{|l|}{ Group D1 } \\
\hline $\mathrm{pH}$ & $7.37 \pm 0.034$ & $7.06 \pm 0.060$ & $7.33 \pm 0.070$ & $7.39 \pm 0.030$ & $7.42 \pm 0.021$ & $7.43 \pm 0.019$ \\
\hline $\mathrm{PCO}_{2}$ (torr) & $38.9 \pm 3.0$ & $84.6 \pm 13.5$ & $38.4 \pm 13.5$ & $37.6 \pm 3.3$ & $38.2 \pm 2.9$ & $39.3 \pm 3.2$ \\
\hline $\mathrm{PO}_{2}$ (torr) & $95 \pm 21$ & $17 \pm 10$ & $97 \pm 51$ & $107 \pm 29$ & $124 \pm 22$ & $113 \pm 28$ \\
\hline $\mathrm{HCO}_{3}^{-}(\mathrm{mM} /$ liter $)$ & $21.5 \pm 0.7$ & $22.4 \pm 1.7$ & $19.4 \pm 1.3$ & $22.0 \pm 0.9$ & $23.7 \pm 1.2$ & $24.8 \pm 1.7$ \\
\hline \multicolumn{7}{|l|}{ Group D2 } \\
\hline $\mathrm{pH}$ & $7.38 \pm 0.040$ & $7.09 \pm 0.011$ & $7.28 \pm 0.090$ & $7.31 \pm 0.114$ & $7.35 \pm 0.119$ & $7.39 \pm .039$ \\
\hline $\mathrm{PCO}_{2}$ (torr) & $37.0 \pm 3.6$ & $63.7 \pm 2.4$ & $35.7 \pm 6.1$ & $40.0 \pm 9.0$ & $35.7 \pm 7.2$ & $39.6 \pm 6.5$ \\
\hline $\mathrm{PO}_{2}$ (torr) & $90 \pm 14$ & $26 \pm 11$ & $84 \pm 35$ & $70 \pm 29$ & $106 \pm 30$ & $109 \pm 33$ \\
\hline $\mathrm{HCO}_{3}^{-}(\mathrm{mM} /$ liter $)$ & $20.8 \pm 1.2$ & $18.1 \pm 1.0 \dagger$ & $16.1 \pm 4.1$ & $19.2 \pm 3.3$ & $19.0 \pm 5.1$ & $23.3 \pm 3.9$ \\
\hline
\end{tabular}

* D1 refers to five rats in group D that had normal BAER following resuscitation. D2 refers to seven rats in group D that had secondary deterioration of BAER following resuscitation.

$\dagger p<0.05$ versus group D1. 
the neurons of the various nuclei, the possibility of a generalized systemic effect of bilirubin cannot be ruled out. Such an effect could also cause attenuation of the entire response.

Progressive cerebral edema in humans has been shown to produce decreases in wave amplitudes and prolongation of latencies of all wave components $(15,21)$ and hypoxic-ischemic brain injury due to asphyxia produces cerebral edema $(22,23)$. Rats in group $\mathrm{C}$, who were asphyxiated but received no bilirubin, did not demonstrate a secondary deterioration in the BAER by the completion of the 1 -h observation period. The presence of bilirubin was needed, in addition to the asphyxial insult, before a portion of the rats demonstrated a secondary progressive deterioration of their BAER. In the brains examined, there was no evidence of brainstem herniation or gross edema.

Low systemic arterial blood pressures alone (and, presumably, a decreased cerebral blood flow) could also account for such a deterioration. However, there were no differences detected in arterial blood pressures between those rats who demonstrated the secondary deterioration, and those who did not.

Three of the seven rats who demonstrated a secondary deterioration in the BAER, had a persistent acidosis following resuscitation. Two had metabolic acidosis and one a respiratory acidosis ( $\mathrm{pH} 7.09, \mathrm{PCO}_{2} 72$ torr). Bratlid et al. (17) have shown that hypercarbia will open the blood brain barrier and allow bilirubin entry into the rat's brain whereas metabolic acidosis will not. Since six of the seven rats did not have hypercarbia in the recovery phase, this could not, by itself, account for the secondary deterioration seen in the BAER.

Hypothermia has been shown to prolong latencies and produce variable effects on amplitudes of the BAER (24). Temperatures of all rats were servocontrolled and remained at control values.

When BAER testing has been attempted in patients with posticteric deafness, there was either no response or a response only to increased intensity of the click stimuli (25), and deterioration of the BAER has been demonstrated in hyperbilirubinemic infants $(6,8,26)$. We do not know if the secondary progressive deterioraton seen in our study was permanent or would have improved over a longer observation time or with exchange transfusion.

We have shown that asphyxia can predispose the adult rat brain to the toxic effects of bilirubin, but we do not know if it is hypoxia, hypercarbia, the resulting hypotension and ischemia, or a combination of these factors that is responsible. Nevertheless, as has been shown by others $(6,8,26)$ the BAER might be useful as a noninvasive means of identifying bilirubin toxicity.

\section{REFERENCES}

1. Jewett DL 1970 Volume-conducted potentials in response to auditory stimuli as detected by averaging in the cat. Electroencephalogr Clin Neurophysiol
28:609-618

2. Jewett DL, Romano MN 1972 Neonatal development of auditory system potentials averaged from the scalp of the rat and cat. Brain Res 36:101-115

3. Jewett DL, Williston JS 1971 Auditory-evoked far fields averaged from the scalp of humans. Brain 94:681-696

4. Fenwick JD 1975 Neonatal jaundice as a cause of deafness. J Laryngol Otol 89:925-932

5. Rozdilsky B, Olszewski J 1961 Experimental study of the toxicity of bilirubin in newborn animals. J Neuropathol Exp Neurol 20:193-304

6. Lenhardt ML, McArtor R, Bryant B 1984 Effects of neonatal hyperbilirübinemia on the brainstem electric response. J Pediatr 104:281-284

7. Rapoport SI 1978 Blood-brain barrier opening by isotonic saline infusion in normotensive and hypertensive animals. Acta Radiol [Diagn] (Stockh) 19:921-932

8. Wennberg RP, Ahlfors CE, Bickers R, McMurtry CA, Shetter JL 1982 Abnormal auditory brainstem response in a newborn infant with hyperbilirubinemia: Improvement with exchange transfusion. J Pediatr 100:624-628

9. Chen H, Lein I-N, Lu T-C 1965 Kernicterus in newborn rabbits. Am J Pathol $46: 331-343$

10. Chen H, Lin C-S, Lein I-N 1966 Ultrastructural studies in experimental kernicterus. Am J Pathol 48:683-711

11. Lucey JF, Hibbard E, Behrman RE, Gallardo E, Windle WF 1964 Kernicterus in asphyxiated newborn rhesus monkeys. Exp Neurol 9:43-58

12. Pepelko WE, Dixon GA 1975 Arterial blood gases in conscious rats exposed to hypoxia, hypercapnia, or both. J Appl Physiol 38:581-587

13. Levine RL, Fredericks WR, Rapoport SI 1982 Entry of bilirubin into the brain due to opening of the blood-brain barrier. Pediatrics 69:255-259

14. Chiueh CC, Sun CL, Kopin IJ, Fredericks WR, Rapoport SI 1978 Entry of [3] H-norephinephrine, [125]I-albumin and Evan's blue from blood into brain following unilateral osmotic opening of the blood-brain barrier. Brain Res 145:291-301

15. Starr A 1976 Auditory brain-stem responses in brain death. Brain 99:543-554

16. Rapoport SI, Thompson HK 1973 Osmotic opening of the blood-brain barrier without associated neurological deficits. Science 180:971

17. Bratlid D, Cashore WJ, Oh W 1984 Effect of acidosis on bilirubin deposition in rat brain. Pediatrics 73:431-434

18. Lending M, Slobody LB, Mestern J 1966 The relationship of hypercapnea to the production of kernicterus. Dev Med Child Neurol 9:145-151

19. Rapoport SI 1975 Experimental modification of blood-brain barrier permeability by hypertonic solutions, convulsions, hypercapnia, and acute hypertension. In: Cserr H, Fenel V, Fenstermacher JD (eds) Fluid Environment of the Brain. Academic Press, New York, pp 61-80

20. Hellmann J, Batton DG, Nardis EE 1983 Regional cerebral blood flow during asphyxia and recovery in newborn dogs. Pediatr Res 17:364(abstr)

21. Uziel A Benezech J 1978 Auditory brain-stem responses in comatose patients: relationship with brain-stem reflexes and levels of coma. Electroencephalogr Clin Neurophysiol 45:515-524

22. Kovnar E, Volpe JJ 1982 Current concepts in neonatal neurology. 1. Hypoxicischemic brain injury. Perinatology-Neonatology 6:51-63

23. Raju TNK, Vidyasagar D, Papazafiratou C 1981 Cerebral perfusion pressure and abnormal intracranial pressure wave forms: their relationship to outcome in birth asphyxia. Crit Care Med 9:449-453

24. Williston JS, Jewett DL 1982 The Q10 of auditory brain stem responses in rats under hypothermia. Auditology 21:457-465

25. Chisin R, Perlman M, Sohmer H 1979 Cochlear and brain stem responses in hearing loss following neonatal hyperbilirubinemia. Ann Otol Rhinol Laryngol 88:352-357

26. Perlman M, Fainmesser P, Sohmer H, Tamari H, Wax Y, Pevsmer B 1983 Auditory nerve-brainstem evoked responses in hyperbilirubinemic neonates. Pediatrics 72:658-664 